\title{
The histopathological effects of levosimendan on liver injury induced by myocardial ischemia and reperfusion
}

\author{
Oktar GL ${ }^{1}$, Demir Amac $N^{1}$, Elmas $\mathrm{C}^{2}$, Arslan $\mathrm{M}^{3}$, Goktas $\mathrm{G}^{2}$, Iriz $\mathrm{E}^{1}$, Erer $\mathrm{D}^{1}$, Zor $\mathrm{MH}^{1}$, Tatar $\mathrm{T}^{1}$ \\ Department of Cardiovascular Surgery, Faculty of Medicine, Gazi University, Ankara, Turkey. \\ mustarslan@gmail.com
}

\begin{abstract}
Background: The aim of this study was to evaluate the histological and immunohistochemical effects of levosimendan on liver injury induced by myocardial ischemia and reperfusion (I/R) in a rat model. Methods: Twenty-four male Wistar Albino rats were randomly divided into the four groups: Group $C$ (Control, $n$ $=6)$, Group I/R $(n=6)$, Group BI (I/R group treated with levosimendan before ischemia, $n=6)$, and Group AI (I/R group treated with levosimendan after ischemia, $n=6$ ). Myocardial I/R was induced by ligation of the left anterior descending coronary artery for 30 min followed by two hours of reperfusion in I/R and I/R+Levosimendan groups. At the end of the study, liver tissue samples were obtained for histopathological and immunohistochemical examination.

Results: Masson Trichrome staining revealed significant hepatocyte degeneration and necrosis most marked in portal acinus Zone 3, especially around the central veins in Group I/R. Histopathological changes in Group Al were more similar to the changes in Group I/R. Milder hepatocellular degeneration was found in Group $\mathrm{BI}$, when compared to groups I/R and AI. Immunohistochemical score was found to be significantly higher in Group I/R compared to groups $\mathrm{C}, \mathrm{BI}$ and $\mathrm{Al}(\mathrm{p}<0.0001)$. The scores in groups $\mathrm{BI}$ and $\mathrm{Al}$ were found to be similar $(\mathrm{p}=0.068)$. Conclusion: Levosimendan ameliorates liver injury induced by myocardial IR, especially when administered before induction of ischemia (Fig. 9, Ref. 37). Text in PDF www.elis.sk.

Key words: levosimendan, myocardial ischemia reperfusion, remote organ, liver injury, i-NOS, rat.
\end{abstract}

\section{Introduction}

Myocardial ischemia and reperfusion (I/R) causes a systemic inflammatory response affecting multiple remote organs during an open heart surgery. Hepatic injury, an infrequent, but serious complication of cardiac surgery, is believed to be a consequence of free-radical generation in the liver and is associated with high rates of morbidity and mortality (1-4).

The incidence of liver injury is increasing worldwide. Viral infection, alcohol or drug toxicity, and many other factors, including $\mathrm{I} / \mathrm{R}$, can cause damage to hepatocytes. Therefore, these factors may cause inflammatory and oxidant reactions in the liver (5-10).

Levosimendan is a relatively new inotropic and vasodilator agent used in the management of acute and chronic heart failure (11). Its positive inotropic effect is mediated by calcium sensitization of contractile proteins, and its vasodilatory and anti-ischemic effects are mediated by the opening of adenosine triphosphate-sensitive potassium channels in vascular smooth muscle cells (11-14).

${ }^{1}$ Department of Cardiovascular Surgery, Faculty of Medicine, Gazi University, Ankara, Turkey, ${ }^{2}$ Department of Histology and Embryology, Faculty of Medicine, Gazi University, Ankara, Turkey, and ${ }^{3}$ Department of Anesthesiology and Reanimation, Faculty of Medicine, Gazi University, Ankara, Turkey

Address for correspondence: M. Arslan, MD, Gazi University Medical Faculty, Department of Anesthesiology and Reanimation, 06510 Ankara, Turkey.

Phone: +90.3122026739
The protective effects of levosimendan are not limited to cardiac tissue. It has been suggested that levosimendan also attenuates I/R injury in the spinal cord, lung, and in the renal tissue (15-17).

The aim of this study was to investigate histological and immunohistochemical effects of levosimendan on liver as a remote organ during an experimental model of myocardial $\mathrm{I} / \mathrm{R}$ injury in rats.

\section{Materials and methods}

\section{Animals and Experimental Protocol}

The experiments were performed in adherence to the National Institutes of Health guidelines on the use of experimental animals. Twenty-four male, Wistar rats, weighing from 250 to $350 \mathrm{~g}$, were housed at constant temperature with $12 / 12 \mathrm{~h}$ periods of light and dark exposure. Animals were allowed to standard rat chow and water ad libitum during an acclimatisation period of at least 5 days prior to use in these experiments. The protocols of this experimental study were approved by the Animal Ethics Committee of Gazi University.

The rats were anesthetized with intramuscular ketamine ( 80 $\mathrm{mg} / \mathrm{kg}$ ) and xylazine $(5 \mathrm{mg} / \mathrm{kg})$ injections. After anesthesia and tracheotomy, a $16 \mathrm{G}$ canula (Medipro Nova Cath ${ }^{\circledR}$ Istanbul, Turkey) was inserted into the trachea and connected to a Rodent model ventilator (Harvard Apparatus Rodent, Inspira asv, Hollstone, USA) with a tidal volume of $15 \mathrm{~mL} / \mathrm{kg}$ at a breathing frequency of 80 cycles $/ \mathrm{min}$. The chest was shaved and each animal was fixed in a supine position on the operating table. The chest 
was opened by a left thoracotomy followed by sectioning the fourth and fifth ribs about $2 \mathrm{~mm}$ to the left of the sternum. Positive-pressure artificial respiration was started immediately with a room air, using a volume of $1.5 \mathrm{ml} / 100 \mathrm{~g}$ body weight at a rate of $60 \mathrm{strokes} / \mathrm{min}$. Sodium heparin $(500 \mathrm{IU} / \mathrm{kg})$ was administered through the tail vein.

After the pericardium was incised, the heart was exteriorized by a gentle pressure on the right side of the rib cage. The left anterior descending (LAD) branch of the left coronary artery was was permanently ligated by passing an $8-0$ silk suture attached to a 10-mm micropoint reverse-cutting needle under the artery. The heart was then carefully replaced in the chest and the rat was allowed to recover for $20 \mathrm{~min}$.

There were four experimental groups (Group C (Control; $n$ $=6$ ), Group IR (ischemia-reperfusion, $n=6$ ), Group L (Levosimendan; $n=6$ ) underwent left thoracotomy and received intravenous Levosimendan without I/R (Simdax $2.5 \mu \mathrm{g} / \mathrm{ml}$, Abbott ${ }^{\circledR}$, Orion Pharma, Espoo, Finland) was administrated via $100 \mu \mathrm{g} / \mathrm{kg}$ intraperitoneal route 30 minutes before ligating the left coronary artery 19 and Group IR-L (I/R- Levosimendan; $\mathrm{n}=6$ ). A small plastic snare was threaded through the ligature and placed in contact with the heart. The artery could then be occluded by applying tension to the ligature (60 $\mathrm{min}$ ), and reperfusion was achieved by releasing the tension (120 min). Sham-operated rats were used as controls. All rats were sacrified and then the liver tissues were quickly removed.

\section{Histopathological evaluation}

Liver biopsy specimens were fixed in $10 \%$ neutral buffered formalin for 72 hours at room temperature, dehydrated in graded alcohol and embedded in paraffin. 4-5 $\mu \mathrm{m}$ sections were cut on a microtome (Leica SM 2000, Germany) and mounted on polylysinecoated slides. Some of tissue samples were stained with Masson Trichrome for the evaluation of ultrastructural changes and the remaining samples were evaluated for inducible nitric oxide synthase (iNOS) expression using immunohistochemical staining.

After incubating overnight at $37^{\circ} \mathrm{C}$ then for $1 \mathrm{~h}$ at $60^{\circ} \mathrm{C}$, slides were de-waxed by two chances of xylene (10 minutes each). The slides were then placed in $100 \%, 96 \%$ and $80 \%$ ethanol for 10 minutes each, followed by two 5 minutes changes of distilled water. Then tissues were circumscribed with a pap pen (Super PAP Pen, PN IM3580, Becman Coulter Company, France). After washing with distilled water and with phosphate buffer saline (PBS, $\mathrm{pH}=7.4$ ), endogenous enzyme were blocked using hydrogen peroxide in 10 minutes. Following a PBS wash, slides were blocked using ready to use Ultra block (Cat: 859043, Lot: 903532A, Invitrogen, USA) in 10 minutes, prior to application of a 1:50 concentration of i-NOS (Cat: sc-651, Lot: H1308, Santa Cruz, USA) for 1 hour. Two PBS rinses preceded secondary antibody (Cat: 859043, Lot: 903532A, Invitrogen, USA) application for 10 minutes. After washing with PBS, slides were exposed to streptavidin peroxidase (Cat: 859043, Lot: 903532A, Invitrogen, USA) for $10 \mathrm{~min}$. Then AEC (3-Amino-9-EthylCarbazole, Lot: 911667A, Invitrogen, USA) was used as chromogen. Afterwards, the slides were counterstained with Mayer's haematoxylin. Slides were examined with Photo-light microscope (DCM4000 Image Analyze System, DFC280 Plus Camera and QWin Programme, Leica, Weetlar, Germany).

\section{Statistical analyses}

Statistical analyses were carried out using the SPSS version 17.0 statistical software package (SPSS Inc., Chicago, IL). The results were expressed as the mean \pm standard deviation (SD). $p$ values $<0.05$ were considered as statistically significant in all statistical analyses.

Kruskal-Wallis test was used to evaluate the difference among the independent groups with normal distribution. In case of a difference between the groups, the comparison was made using the Mann-Whitney U test.

\section{Results}

\section{Masson Trichrome Staining}

In histopathological evaluation of Masson Trichrome stained sections, there were no pathological changes in liver tissue of the control group (Figs 1A, B, C).

Portal acinus Zone 1 hepatocytes were in normal histologic structure in the Group I/R. Zone 3 hepatocytes near the central
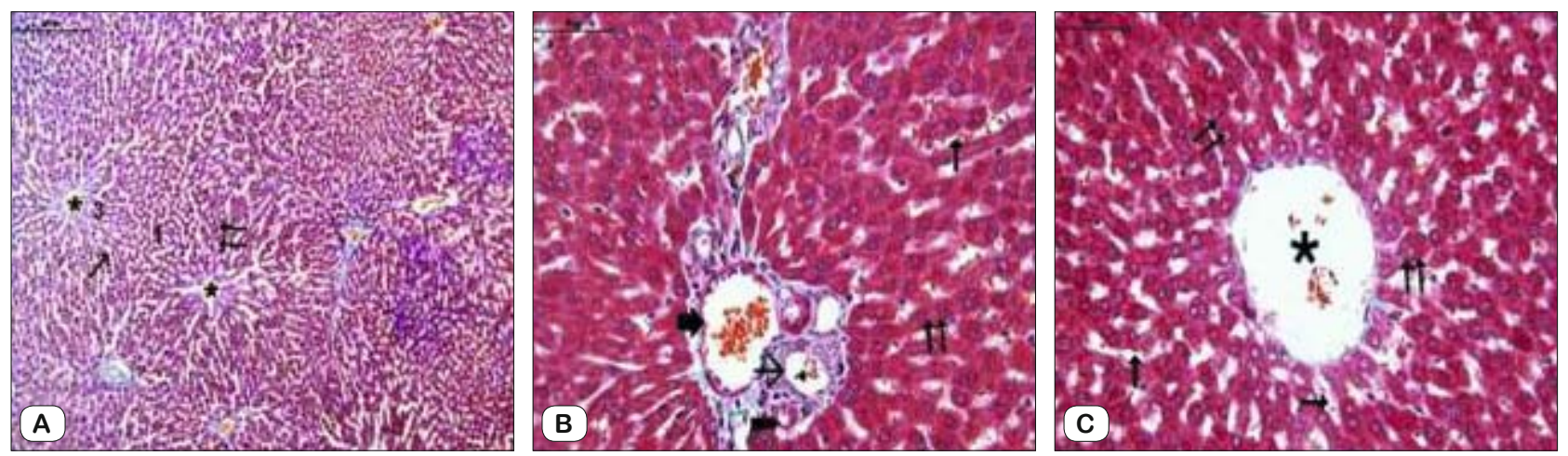

Fig. 1A, B, C. Section of the liver tissue in Group C (control group). 1 - Hepatic acinus Zone 1, 3 - Hepatic acinus Zone 3, * - Vena centralis, $\exists$ - Hepatocytes, $\rightarrow$ - Sinusoids, $\Rightarrow$ - Portal vein, $\rightarrow-$ Hepatic artery, $\rightarrow-$ Bile duct (Masson Trichrome AX100,B-CX400). 

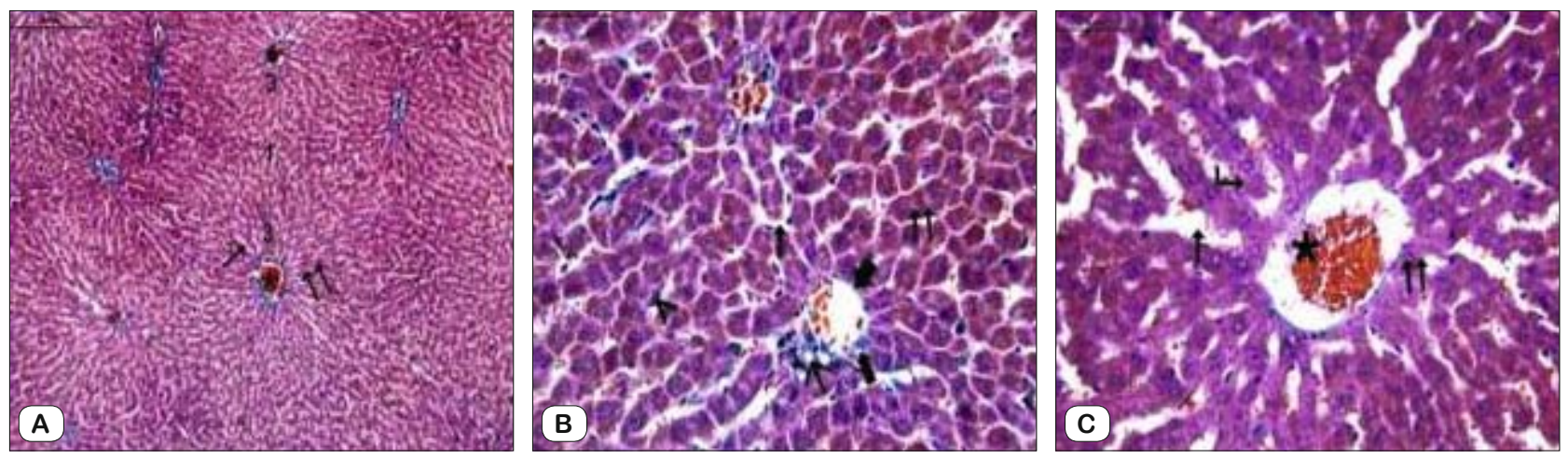

Fig. 2A, B, C. Section of the liver tissue in Group I/R. 1 - Hepatic acinus Zone 1, 3 - Hepatic acinus Zone 3, $\star$ - Vena centralis, $\rightrightarrows$ - Hepatocytes, $\rightarrow$-Sinusoids, $\Rightarrow$ - Portal vein, - - Hepatic artery, $\rightarrow$ - Bile duct, $>-$ Kuppfer cell, $\llcorner$ - Necrotic hepatocyte (Masson Trichrome AX100,B-CX400).
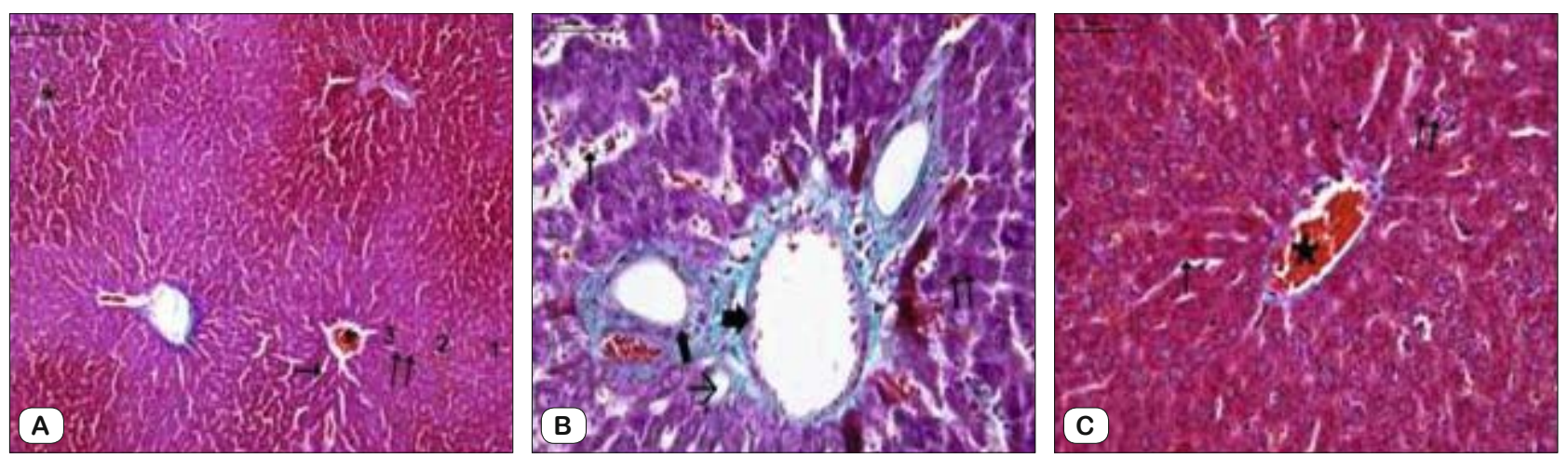

Fig. 3A, B, C. Section of the liver tissue in Group BI (IR+levosimendan before ischemia) 1 - Hepatic acinus Zone 1, 2 - Hepatic acinus Zone 2, 3 - Hepatic acinus Zone $3, \star$ - Vena centralis, $\rightrightarrows$ - Hepatocytes, $\rightarrow$ - Sinusoids, $\Rightarrow$ - Portal vein, $\rightarrow-$ Hepatic artery, $\rightarrow-$ Bile duct (Masson Trichrome AX100,B-CX400).
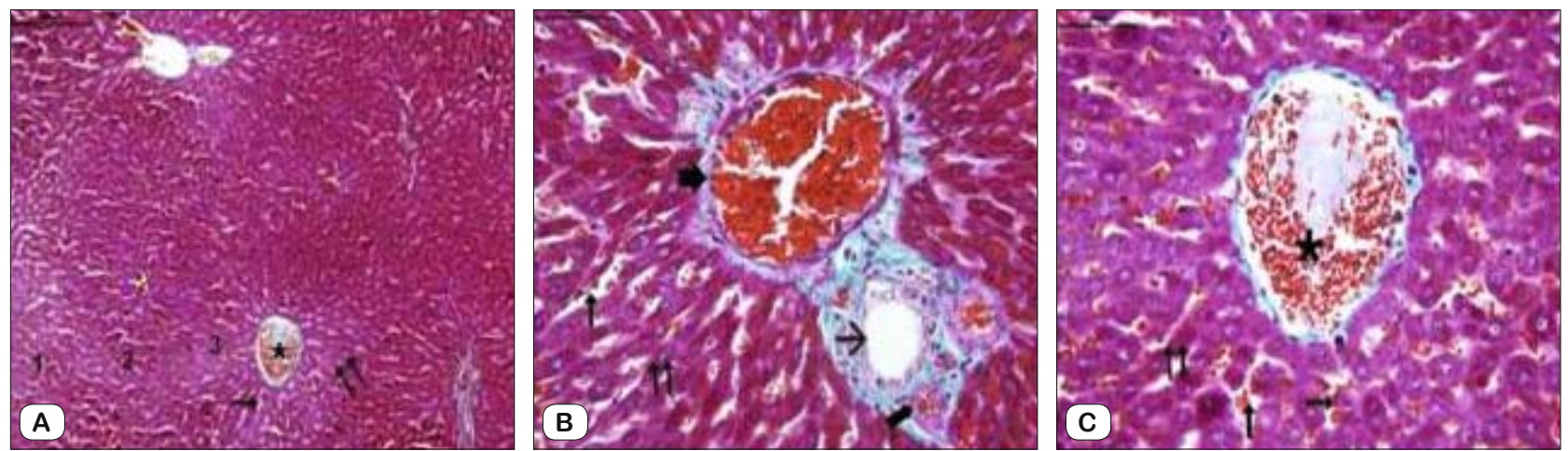

Fig. 4A, B, C. Section of the liver tissue in Group AI (IR+levosimendan after ischemia) 1 - Hepatic acinus Zone 1,2 - Hepatic acinus Zone 2, 3 - Hepatic acinus Zone 3, $\star$ - Vena centralis, $\rightrightarrows$ - Hepatocytes, $\rightarrow$ - Sinusoids, $\Rightarrow$ - Portal vein, $\rightarrow-$ Hepatic artery, $\rightarrow-$ Bile duct $($ Masson Trichrome AX100,B-CX400).

vein were noted to have degenerated structure with vacuolar cytoplasm and pale staining. At a higher magnification, significantly degenerated and necrotic hepatocytes were observed around the central veins and also significant oedema and degeneration were noted in the sinusoids. Zone 1 hepatocytes at the portal acinus near the blood vessels in portal space were structurally normal and the sinusoids, endothelial cells and Kuppfer cells also revealed no pathological changes (Figs 2A, B, C).
In Group BI, portal acinus Zone 1 and partially Zone 2 hepatocytes were found to be normal, but Zone 3 hepatocytes, particularly the ones near the central veins revealed pale staining with degeneration and necrosis. The evaluation at a higher magnification supported these findings. Milder histopathological changes were observed in the Group BI, when compared to the Group AI (Figs 3A, B, C).

In the evaluation at a low magnification, the structures in the 

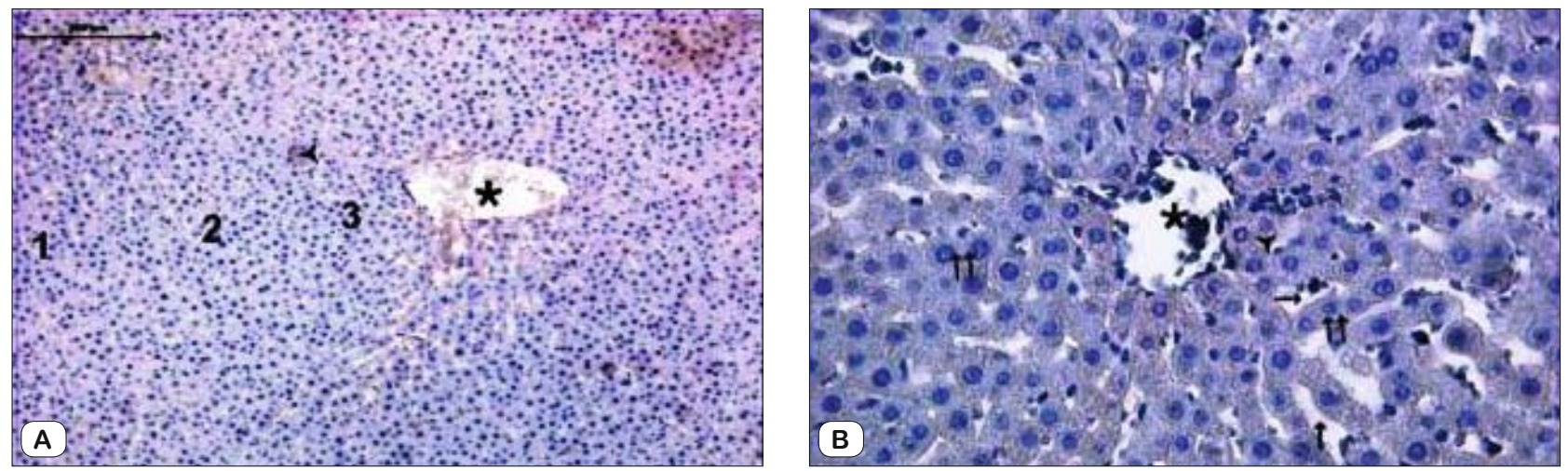

Fig. 5A, B. I-NOS expression ( $A$ ) in Group C (control group). 1 - Portal acinus Zone 1, 2 - Portal acinus Zone 2, 3 - Portal acinus Zone 3 , $\star$ - Vena centralis, $\rightrightarrows$ - Hepatocytes, $\rightarrow$ - Sinusoids (Immunohistochemical staining).
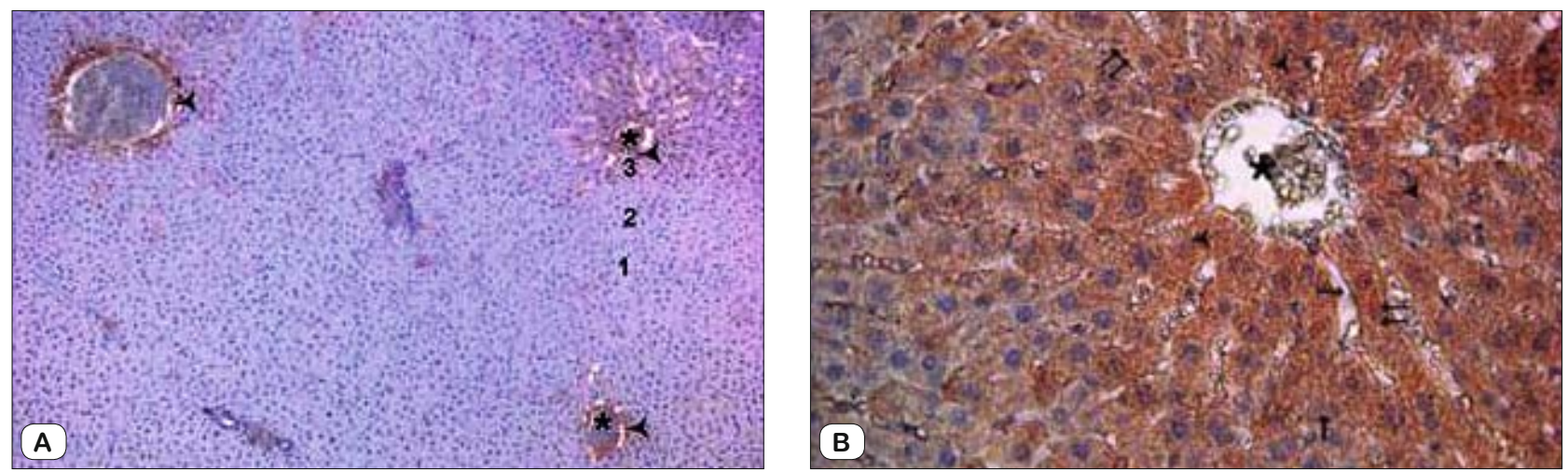

Fig. 6A, B. I-NOS expression ( $\curlywedge$ ) in Group I/R. 1 - Portal acinus Zone 1, 2 - Portal acinus Zone 2, 3 - Portal acinus Zone 3, * - Vena centralis, $\rightrightarrows$ - Hepatocytes, $\rightarrow$ - Sinusoids (Immunohistochemical staining).
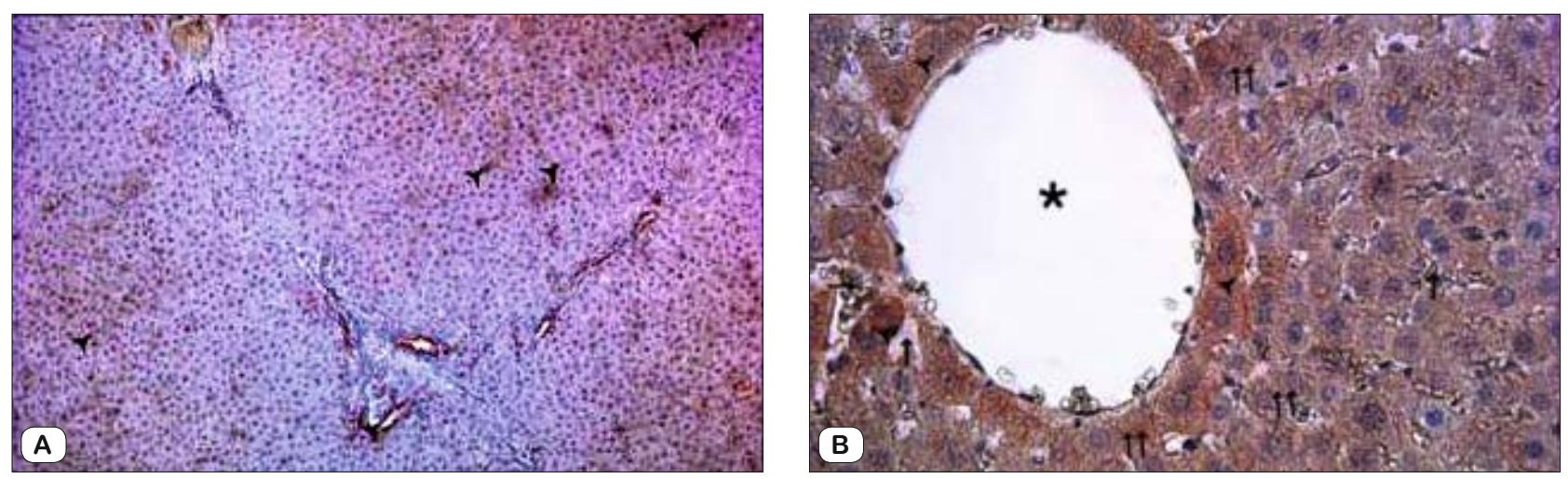

Fig. 7A, B. I-NOS expression ( $\curlywedge$ ) in Group BI (IR+levosimendan before ischemia). 1 - Portal acinus Zone 1, 2 - Portal acinus Zone 2, 3 - Portal acinus Zone 3, $\star$ - Vena centralis, $\rightrightarrows$ - Hepatocytes, $\rightarrow$ - Sinusoids (Immunohistochemical staining).

portal triad and the central veins were observed to be normal in the Group AI. Although the hepatocytes in portal acinus Zone 1, 2 and 3 showed degeneration with pale staining, the hepatocytes near the portal triad were observed to be structurally normal in some areas. Significant oedema was noted in Zone 3 sinusoids. At a higher magnification, structures of the portal triad and the hepatocytes near this zone were noted to be normal, while the hepatocytes in portal acinus Zone 3 near central veins revealed cyto- plasmic degeneration and necrosis. Significant sinusoidal oedema was also observed at this zone (Figs 4A, B, C).

\section{Immunohistochemical findings}

The results of immunohistochemical evaluation supported the findings Masson-Trichrome staining. I-NOS immunoreactivity was very weak in the control group at low and high magnifications (Figs 5A, B). 

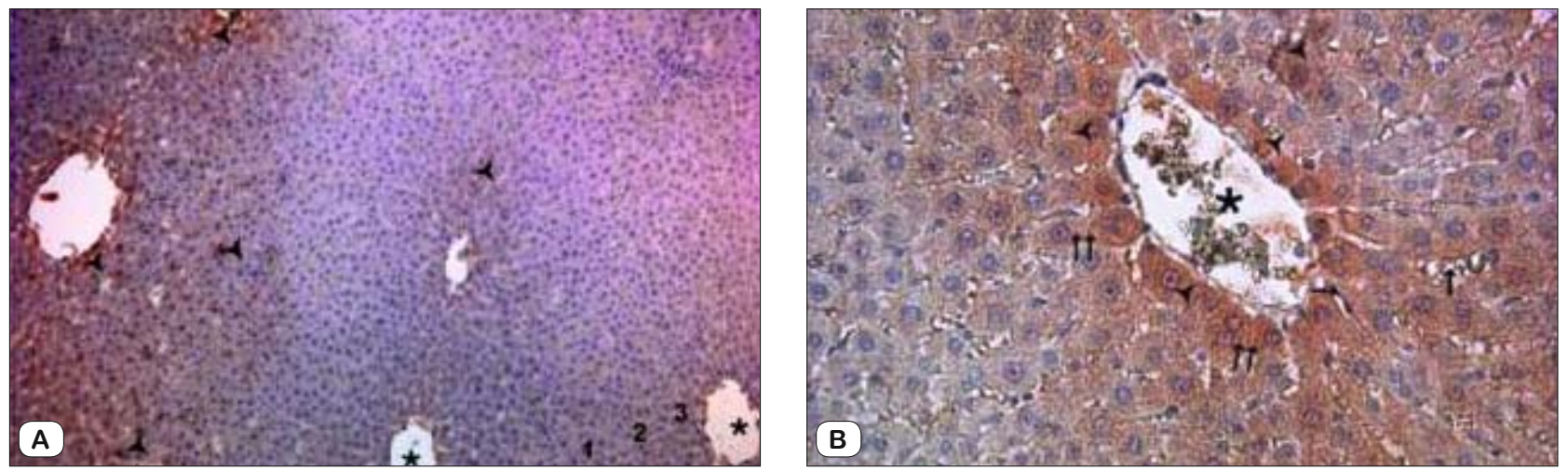

Fig. 8A, B. I-NOS expression ( $\curlywedge$ ) in Group AI (IR+levosimendan after ischemia). 1 - Portal acinus Zone 1, 2 - Portal acinus Zone 2, 3 - Portal acinus Zone $3, \star$ - Vena centralis, $\rightrightarrows$ - Hepatocytes, $\rightarrow$ - Sinusoids (Immunohistochemical staining).

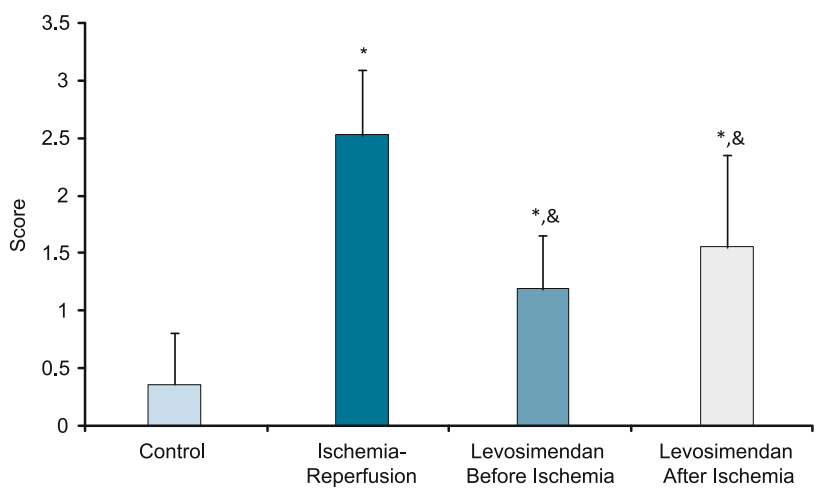

Fig. 9. Immunohistochemical evaluation of the study groups. Each bar represents the mean $\pm \mathrm{sd}$. * $\mathbf{p}<0.05$ compared to the Group Control $\& \mathbf{p}<0.05$ compared to the Group $\mathrm{I} / \mathrm{R}$.

In Group I/R, moderate to strong i-NOS expression was observed particularly in portal acinus Zone 3 hepatocytes. This finding suggested that hepatocytes of Zone 3 may be the cells affected mostly by I/R. I-NOS immunoreactivity was negative in portal acinus Zone 1 and weak in Zone 2 (Figs 6A, B).

In the Group AI, a stronger i-NOS expression was noted particularly in Zone 3 hepatocytes of portal acinus near central veins, whereas the immunoreactivity was found to be moderate in the assessment of i-NOS expression in Group BI (Figs 7A, B and 8A, B).

There was a statistically significant difference among the groups, when they were compared among themselves by means of immunohistochemical scores $(p<0.0001)$. Immunohistochemical score was found to be significantly higher in the Group I/R compared to the groups $\mathrm{C}, \mathrm{BI}$ and $\mathrm{AI}(\mathrm{p}<0.0001)$. Moreover, the immunohistochemical scores were also significantly higher in levosimendan groups than the score in the Group $\mathrm{C}(\mathrm{p}<0.0001)$. The scores in groups BI and AI were found to be similar ( $\mathrm{p}=$ 0.068) (Fig. 9).

\section{Discussion}

Although restoration of blood flow to an ischemic organ is essential to prevent irreversible tissue injury, reperfusion of isch- emic areas may contribute to further tissue damage. The generation of reactive oxygen species subsequent to reoxygenation inflicts tissue damage and initiates a cascade of deleterious cellular responses leading to inflammation, cell death, and ultimate organ failure (18). I/R injury may extend beyond the ischemic area at risk to include injury of remote non-ischemic organs (19). The remote effects of I/R are most frequently observed in the pulmonary, renal, hepatic and cardiovascular systems, and can result in the development of the systemic inflammatory response and multiple organ dysfunction syndromes, both of which account for $30-40 \%$ of the mortality in intensive care units (20). Hepatic $\mathrm{I} / \mathrm{R}$ injury was mainly observed following major liver surgery, transplantation, trauma and sepsis and may cause metabolic and structural hepatic damage $(21,22)$. Severe early ischemic hepatic injury after cardiac surgery is considered as a rare postoperative complication with limited mention in literature and is likely to significantly complicate the postoperative course of heart surgery patients $(23,24)$.

The cardioprotective effects of levosimendan are well-established. The first anti-ischemic effects of levosimendan were published in 1994 in isolated rabbit hearts by Rump et al (25). The authors showed that the left ventricular pressure and coronary blood flow were significantly increased by levosimendan after occlusion of the first postero-lateral branch of the circumflex artery for $120 \mathrm{~min}$. It has been shown to have an anti-ischemic effect, to prevent the development of arrhythmias during acute myocardial infarction and to decrease myocardial infarct size and produce cardioprotective effects while simultaneously enhancing ventricular contractile function in animal studies (26-31). However, no sufficient data exist about the effects of levosimendan against hepatic ischemia-reperfusion injury. To our knowledge, this is the first study to evaluate the effects of levosimendan on hepatic injury induced by myocardial $I / R$ in an experimental model.

A number of in vitro and in vivo studies including models of acute coronary ischemia and cardiac dysfunction showed that levosimendan provided myocardial protection by inducing preconditioning of the myocardium against peri-operative I/R injury and by involving apoptotic pathway (32-36). 
241-247

The findings in Masson Trichrome staining and immunohistochemical evaluation showed that portal acinus Zone 3 was the most affected area from I/R injury and then zones 2 and 1 , respectively. Histopathological changes in the Group AI were more similar to the changes in Group I/R and this finding showed that the rats administered levosimendan after ischemia were more vulnerable to hepatic I/R injury. Milder hepatocellular degeneration was found in Group BI, when compared to the groups I/R and AI.

Sareila et al reported that levosimendan and dextrosimendan decreased iNOS promoter activity, iNOS expression and NO production (37). In this study, iNOS levels were found to be significantly lower in levosimendan groups compared to the $\mathrm{I} / \mathrm{R}$ group. The upregulation of $\mathrm{iNOS}$ in Group I/R means that $\mathrm{I} / \mathrm{R}$ stimulates DNA damage. However, in levosimendan groups, the downregulation of iNOS showed that levosimendan had protective effects on $\mathrm{I} / \mathrm{R}$ related cell damage. Furthermore, it also showed the beneficial effect of levosimendan on cellular stress. These pathological findings were well correlated with previously reported studies.

Pagel et al examined and compared the effects of levosimendan, pimobendan, and milrinone on regional tissue perfusion by use of the radioactive microsphere technique in dogs and reported that levosimendan increased blood flow to the small intestine and liver and reduced vascular resistance in these organs (38). This result indicated that levosimendan might also increase regional tissue perfusion during $\mathrm{I} / \mathrm{R}$.

In conclusion, the results of this study indicated that administration of levosimendan before ischemia might be more effective against hepatic $\mathrm{I} / \mathrm{R}$ injury. We recognize the limitations of simulating human cardiac surgery induced $\mathrm{I} / \mathrm{R}$ injury using a rat model. Other aspects of these findings including clinical significance and practical applications merit further experimental and clinical investigations.

\section{References}

1. Diaz GC, Moltra V, Sladen RN. Hepatic and renal protection during cardiac surgery. Anesthesiol Clin 2008; 26: 565-590.

2. Colak C, Parlakpinar H, Ozer MK, Sahna E, Cigremis Y, Acet A. Investigating the protective effect of melatonin on liver injury related to myocardial ischemia-reperfusion. Med Sci Monit 2007; 13: BR251-254.

3. Jaeschke H. Mechanisms of Liver Injury. II. Mechanisms of neutrophilinduced liver cell injury during hepatic ischemia-reperfusion and other acute inflammatory conditions. Am J Physiol Gastrointest Liver Physiol 2006; 290: G1083-1088.

4. Giakoustidis D, Papageorgiou G, Iliadis S, Giakoustidis A, Kostopoulou E, Kontos $\mathbf{N}$ et al. The protective effect of alpha-tocopherol and $\mathrm{GdCl}(3)$ against hepatic ischemia/reperfusion injury. Surg Today 2006; 36: $450-456$.

5. Decker K. Biologically active products of stimulated liver macrophages (Kupffer cells). Eur J Biochem 1990; 192: 245-261.

6. Hou G, Quin P, Ren G. Effect of anthocyanin-rich extract from black rice (Oryza sativa L. Japonica) on chronically alcohol-induced liver damage in rats. J Agric Food Chem 2010; 58: 3191-3196.
7. Lapeyre-Mestre M, de Castro AM, Bareille MP, Del Pozo JG, Requejo AA, Arias LM et al. Non-steroidal anti-inflammatory drug-related hepatic damage in France and Spain: analysis from national spontaneous reporting systems. Fundam Clin Pharmacol 2006; 20: 391-395.

8. Jaeschke H, Williams CD, Ramachandran A, Bajt ML. Acetaminophen hepatotoxicity and repair: the role of sterile inflammation and innate immunity. Liver Int 2012; 32: 8-20.

9. Morariu AM, Loef BG, Aarts LP, Rietman GW, Rakhorst G, van Oeveren W et al. Dexamethasone: benefit and prejudice for patients undergoing on-pump coronary artery bypass grafting: a study on myocardial, pulmonary, renal, intestinal, and hepatic injury. Ches. 2005; 128: 2677-2687.

10. McCutcheon CA, Orme RM, Scott DA, Davies MJ, McGlade DP. A comparison of dexmedetomidine versus conventional therapy for sedation and hemodynamic controlduring carotid endarterectomy performed under regional anesthesia. Anesth Analg 2006; 102: 668-675.

11. Rognoni A, Lupi A, Lazzero M, Bongo AS, Rognoni G. Levosimendan: From Basic Science to Clinical Trials. Recent Pat Cardiovasc Drug Discov 2011; 6: 9-15.

12. Toller WG, Stranz C. Levosimendan, a new inotropic and vasodilatory agent. Anesthesiology 2006; 104: 556-569.

13. Erdei N, Papp Z, Pollesello P, Edes I, Bagi Z. The levosimendan metabolite OR-1986 elicits vasodilation by activating the K(ATP) and BK(Ca) channels in rat isolated arterioles. Br J Pharmacol 2006; 148: 696-702.

14. Kaheinen P, Pollesello P, Levijoki J, Haikala H. Levosimendan increases diastolic coronary flow in isolated guinea pig heart by opening ATPsensitive potassium channels. J Cardiovasc Pharmacol 2001; 37: 367-374.

15. Katircioglu SF, Seren M, Parlar AI, Turan NN, Manavbasi Y, Aydog G et al. Levosimendan effect on spinal cord ischemia-reperfusion injury following aortic clamping. J Card Surg 2008; 23: 44-48.

16. Yasa H, Yakut N, Emrecan B, Ergunes K, Ortac R, Karahan N et al. Protective effects of levosimendan and iloprost on lung injury induced by limb ischemia-reperfusion: A rabbit model. J Surg Res 2008; 147: 138-142.

17. Yakut N, Yasa H, Bahriye Lafci B, Ortac R, Tulukoglu E, Aksun $\mathbf{M}$ et al. The influence of levosimendan and iloprost on renal ischemiareperfusion: An experimental study. Interact Cardiovasc Thorac Surg 2008; 7: 235-239.

18. Fondevila C, Busuttil RW, Kupiec-Weglinski JW. Hepatic ischemia/reperfusion injury--a fresh look. Exp Mol Pathol 2003; 74: 86-93.

19. Eltzschig HK, Collard CD. Vascular ischaemia and reperfusion injury. Br Med Bull 2004; 70: 71-86.

20. Neary P, Redmond HP (1999) Ischaemia-reperfusion injury and the systemic inflammatory response syndrome. In Grace PA, Mathie RT (Eds). Ischaemia-Reperfusion Injury. Oxford: Blackwell Science, 123-136.

21. Shin T, Kuboki S, Huber N, Eismann T, Galloway E, Schuster R et al. Activation of peroxisome proliferator-activated receptor-gamma during hepatic ischemia is age-dependent. J Surg Res 2008; 147: 200-205.

22. van Gulik TM, de Graaf W, Dinant S, Busch OR, Gouma DJ. Vascular occlusion techniques during liver resection. Dig Surg 2007; 24: 274-783.

23. Raman JS, Kochi K, MD, Morimatsu H, Buxton B, Bellomo R. Severe ischemic early liver injury after cardiac surgery. Ann Thorac Surg 2002; 74: 1601-1606.

24. Rump AF, Acar D, Rosen R, Klaus W. Functional and antiischaemic effects of the phosphodiesterase inhibitor levosimendan in isolated rabbit hearts. Pharmacol Toxico. 1994; 74: 244-248. 
25. Pollesello P, Papp Z. The cardioprotective effects of levosimendan: preclinical and clinical evidence. J Cardiovasc Pharmacol 2007; 50: $257-263$

26. Lepran I, Papp JG. Effect of long-term oral pretreatment with levosimendan on cardiac arrhythmias during coronary artery occlusion in conscious rats. Eur J Pharmacol 2003; 464: 171-176.

27. Kersten JR, Montgomery MW, Pagel PS, Warltier DC. Levosimendan, a new positive inotropic drug, decreases myocardial infarct size via activation of K(ATP) channels. Anesth Analg 2000; 90: 5-11.

28. Du Toit EF, Muller CA, McCarthy J, Opie LH. Levosimendan: effects of a calcium sensitizer on function and arrhythmias and cyclic nucleotide levels during ischemia/reperfusion in the Langendorff-perfused guinea pig heart. J Pharmacol Exp Ther 1999; 290: 505-514.

29. Leprán I, Pollesello P, Vajda S, Varró A, Papp JG. Preconditioning effects of levosimendan in a rabbit cardiac ischemia-reperfusion model. J Cardiovasc Pharmacol 2006; 48: 148-152.

30. Papp JG, Pollesello P, Varró AF, Végh AS. Effect of levosimendan and milrinone on regional myocardial ischemia/reperfusion-induced arrhythmias in dogs. J Cardiovasc Pharmacol Ther 2006; 11: 129-135.

31. Maytin M, Colucci WS. Cardioprotection: a new paradigm in the management of acute heart failure syndromes. Am J Cardiol 2005; 96 : $26 \mathrm{G}-31 \mathrm{G}$.
32. Louhelainen M, Vahtola E, Kaheinen P et al. Effects of levosimendan on cardiac remodeling and cardiomyocyte apoptosis in hypertensive Dahl/Rapp rats. Br J Pharmacol 2007; 150: 851-861.

33. du Toit E F, Genis A, Opie LH, Pollesello P, Lochner A. A role for the RISK pathway and K(ATP) channels in pre- and post-conditioning induced by levosimendan in the isolated guinea pig heart. $\mathrm{Br} \mathrm{J}$ Pharmacol 2008; 154: 41-50.

34. Meyer K, Schipke J, Klocke RC, Gams E, Korbmacher B. Inotropic, vasodilating and preconditioning actions of levosimendan in the heart. Thorac Cardiovasc Surg 2008; 56: 379-385.

35. Grossini E, Caimmi PP, Platini F, Molinari C, Uberti F, Cattaneo M et al. Modulation of programmed forms of cell death by intracoronary levosimendan during regional myocardial ischemia in anesthetized pigs. Cardiovasc Drugs Ther 2010; 24: 5-15.

36. Sareila O, Korhonen R, Auvinen H, Hämäläinen M, Kankaanranta $\mathbf{H}$, Nissinen E et al. Effects of levo- and dextrosimendan on NF-kappaBmediated transcription, iNOS expression and NO production in response to inflammatory stimuli. Br J Pharmacol 2008; 155: 884-895.

37. Pagel PS, Hettrick DA, Warltier DC. Influence of levosimendan, pimobendan, and milrinone on the regional distribution of cardiac output in anaesthetized dogs. Br J Pharmacol 1996; 119: 609-615.

Received September 9, 2013. Accepted May 20, 2014. 